\title{
The Contribution of Emotionally Focused Couples Therapy
}

\author{
Susan M. Johnson
}

Published online: 22 February 2007

(C) Springer Science+Business Media, LLC 2007

\begin{abstract}
This article describes emotionally focused couple therapy and the contribution of this model to the field of couple therapy. A focus on emotional processing in the present moment, on process factors and on a genuine empathic connection with both clients is at the heart of this model. The creation of new patterns of emotional responses results in the creation of key new interactional responses. EFT is empirically validated on several levels: on the level of treatment outcome, and on the levels of the relational theory in which it is based and key moments and factors in the change process.
\end{abstract}

\section{Keywords Emotion $\cdot$ Attachment $\cdot$ Couples therapy}

What does the humanistic approach, exemplified by Emotionally Focused Therapy (EFT, Johnson, 2004) offer the couple therapist? In general, it offers a systematic, well documented, empirically validated model of intervention that is integrated with systemic perspectives, and so combines intrapsychic and interpersonal dimensions. It is also a model that stands firmly on a rich and well researched theory of close relationships, namely attachment theory (Johnson, Hunsley, Greenberg, \& Schindler, 1999; Johnson, 2006; Johnson, 2003) and is consonant with the recent observational research on the nature of marital distress and satis-

\section{S. M. Johnson}

University of Ottawa,

Ottawa, Canada

S. M. Johnson

Alliant University,

San Diego, USA

S. M. Johnson $(\bowtie)$

Ottawa Couple \& Family Institute, Center for EFT,

Ottawa, Canada

e-mail: soo@magma.ca faction (Gottman, 1999; Huston, Caughlin, Houts, Smith, \& George, 2001). More specifically though, what do the humanistic elements of EFT offer the practising couple therapist? The humanistic contribution might be summarized as follows:

\section{Basic elements of EFT for couples}

First, the goal of therapy is more substantial than the alleviation of symptoms or pragmatic problem solving. The focus is on the whole person rather than the problem that brings the client to therapy. Health in this model is the ability to be open to experience, flexible in responding to one's environment and to feel empowered to choose and actively construct one's daily life and relationships with others. The humanistic therapist takes a stance that all clients are capable of growth and agency, if they are given support and validation.

Clinical experience and research results from Johnson and Greenberg (1985) suggest that distressed partners have the "skills" and resources necessary to communicate effectively and positively. They simply cannot access them when flooded with anxiety and trapped in negative self-reinforcing interactional cycles. Problems arise then from lack of or denial of awareness, constriction in processing ongoing experience so that this experience cannot be understood and trusted, a lack of coherence where emotion cannot be integrated with action and cognition, or where elements of the self are in conflict. In marital distress these issues result in partners showing and seeing less and less of each other, sending conflicting messages (e.g. asking in an attacking, belittling way for reassurance and connection), and being caught in negative interaction patterns, such as demand-withdraw. The humanistic therapist does not get caught in the trap of labelling and pathologizing partners or relationships and so is 
able to convey hope and the expectation that partners will be able to shape and improve their connection with each other.

Second, this model specifically outlines the therapeutic relationship that is a necessary condition for growth and change. It assumes that the therapist's acceptance and empathy are powerful in and of themselves in that they create the safety where difficult experience can be encountered and assimilated and where risks can be taken. Empathy here is an active leap of imagination where the therapist connects with and processes core experiences with each client, discovering that experience as it unfolds. Both Rogers (1951) and Bowlby (1969) believed that all responses are basically reasonable and adaptive if they are understood in context. The humanistic therapist then joins each client where that client is and validates his or her attempts to survive, rather than assessing a "problem" and then asking clients to be somewhere else. So, an EFT therapist will accept and work with a client's silence or rage, rather than offering immediate alternatives or attempting to modify this response. The necessity for defensive, rationalizing or justifying behaviours on the part of distressed partners is then minimized.

This model involves a way of being for the therapist, not just the implementation of a set of techniques. The therapist attempts to be open, egalitarian, authentic and transparent in session so that therapy becomes a safe haven where exploration is possible. The therapist is part of the process and the journey of change. The nature of the therapeutic alliance has been found to account for $20 \%$ of the variance in outcome in EFT (Johnson \& Talitman, 1996). Each couple is then a learning opportunity for the therapist and a genuine human encounter. As clients explore the "frightening crannies of inner experience" (Rogers, 1961, p. 34) and risk connecting with each other, the therapist stands with them and discovers this experience.

Third, a humanistic intervention such as EFT is both parsimonious and salient, that is it gets to the heart of the matter as experienced by clients in distressed relationships in the present. Couples' experience of the salience of EFT is reflected in the fact that drop-out rates are generally extremely low in EFT studies and clinical practice, and results appear to be stable, even for high risk couples (Clothier, Manion, Gordon Walker \& Johnson, 2001). The focus of therapy is the moment to moment unfolding of salient emotionally laden experience and interactions as they occur and as they are newly constructed by the therapist and the partners. It is about immediate experience and a couple's international dance as they are lived. The therapist slows down the drama of interaction and helps clients connect more fully with and expand inner experiences and interactional responses. The therapist does not get caught in the myriad of content issues that couples bring to a session or in the intricacies of past histories and unconscious desires. Instead, he or she focuses on being a process consultant who helps partners discover the "order in experience" (Rogers, 1961, p. 24), and then, step by step, create new responses that renew the relationship. Therapists have repeatedly criticised researchers and psychotherapy model builders for omitting a focus on what happens in session and how to pragmatically move each session in a positive direction. The EFT model outlines the process of change in 9 steps (Johnson, 2004) that capture a couples' progress from the de-escalation of their negative interactional cycle, to the creation of new cycles that include powerful bonding interactions, to consolidation and integration. Key change events have also been outlined and therapist interventions that move these events forward delineated (Bradley \& Furrow, 2004).

The focus on the present moment and "mining the moment" (Johnson, 2004), is an essential part of EFT. As Stern suggests $(2004$, p. 31), "the present moment has been relatively but not wholly ignored by psychology." Experiential therapies make a powerful contribution here in stating the power of the present and offering ways to work with it. An EFT couple therapist, using reflection and evocative questions, will hold a moment up to the light and, with the couple, explore its rich and not yet articulated implications. The therapist can take, what Stern calls the "architecture" of the present moment and explicate the "emotional story" underlying it and the choices made as this moment unfolds. So when an isolated partner who is desperate for contact attacks her partner as he risks reaching for her, the therapist stays with this moment and, in a validating manner, helps her explore this response. Distrust and self-protection emerge as the backdrop to this response, but it is examined and chunked into cues, bodily responses, meaning construction, action sequences and the impact of her response on the relationship, which is that, as she pushes him away, he moves into further hopeless and inaccessibility. This one response can prevent the transformation of a couples' negative cycle and the creation of trust. If it is expanded into a statement of fear and vulnerability that evokes the husband's caring, this moment can be the beginning of a new relationship. These moments are rich. They show characteristic ways that partners connect with themselves and with each other.

Fourth, perhaps the greatest contribution of all is the humanistic focus on emotion. Emotions are the blueprints for interactions with attachment figures. They are the music of the attachment dance. There has been more and more acknowledgement in recent years of the power of affective engagement and new corrective emotional experience to create change in psychotherapy, even in cognitive therapy (Wiser \& Goldfried, 1998). In couple therapy, however emotion has generally been marginalized (Johnson, 2005a, b), even though new research suggests that emotion is adaptive and essential in basic processes such as decision making and choice 
(Damasio, 1994). Emotion is powerful and compelling. and while more and more general research is emerging telling us that emotion is a force for adaptation and that the suppression of emotion is harmful (Gross, 2001), it is difficult to use emotion in the service of change unless you have a clear map to intervention.

EFT uses emotion to orient and focus the session on key moments and issues, to guide meaning making and to "move" partners into new actions and responses. New emotional signals reorganize and renew a distressed relationship. The EFT therapist focuses on the six key emotions: joy, surprise, shame, fear, anger and sadness. He or she helps partners access, engage with emotional responses while, at the same time, keeping a "working distance" so that these responses can be revised and evoked to create new positive interactions. The therapist works to create emotional safety and engagement. Emotional engagement and responsiveness is emerging more and more in the marital literature as the key predictor of marital happiness, rather than factors such as conflict containment. In marriage and in therapy, to simply label emotion or to have insight into it does not seem to be that useful. The EFT therapist tracks, reflects and often heightens emotion, moving partners from reactive secondary affects such as irritation/anger to more primary deeply felt underlying emotions such as fear and sadness. The therapist will also help couples engage with and "sort" emotional experiences and,thus, order them. For example, hurt is a mixture of anger, sadness and fear, but usually one of these emotions will stand out and organize a partner's responses. The fear of abandonment, for example, may be crucial in hurt experiences for a partner in couple therapy. Deep emotional experiencing in key change events has been found to predict recovery from relationship distress in EFT (Johnson \& Greenberg, 1988). In general, the EFT therapist works to deepen and distill primary emotions - to change the music and so change the dance of distress.

From the humanistic perspective, it is useful for all therapists to know how to empathically connect with clients, to stay in the present moment and reconstruct that moment, and how to use new emotional experience to build new emotionally salient interactions. We can now turn to look at the interventions that form the basis of the EFT model.

\section{Therapeutic interventions}

The two tasks of the EFT therapist are: (1) the accessing, deepening and distilling key emotional experience and (2) creating new responses and interaction patterns that allow for more secure bonding between spouses. These tasks are completed using the interventions given below:
Empathetic tracking an reflection

Tracking and reflecting inner emotional realities and interpersonal responses are the most basic interventions in EFT. As Rogers suggested (1951) this reflection better orders and deepens engagement with experience. It allows the therapist to slow and to focus the session and at the same time to validate the client's perceptions. Clients feel heard and, at the same time, they have their experience presented to them again, perhaps placed in an expanded context, such as the interactional cycle they create with their spouse, or the overall attachment perspective that EFT uses to understand adult love. The therapist follows and also guides each client's experience as it unfolds, paying particular attention to strong emotion. So, in a second session, a therapist might use reflection to focus a client on her own emotion rather than her partner's faults. The therapist might say to a client who is blaming her partner in a hostile angry way, "If I am hearing you right, Julie, and please correct me if I do not quite understand, you are saying to Tom that you get angry when Tom says that you nag him. That is hard for you to hear. As you stated, you experience him as "somewhere else" a lot of the time. And that makes you very angry?" The therapist tunes into the client and stays with her emotion, even if that emotion is negative and problematic in terms of the client's goals and needs.

\section{Validating each person's experience}

Validation is also a key intervention in EFT. The explicit validation of the therapist encourages clients to allow and explore their emotional reactions, rather than become mired in avoidance or anxiety. Clients do not need to defend or justify themselves if acceptance is a given. Validation is an antidote to the narrow presentation of self and experience arising from self-criticism or fears of judgement from others. So the therapist notes to the clients above, "It is natural for you to get angry to, as you said "get his attention". Most of us do this when we cannot reach a loved one or get that person to respond to us. It is very painful and so we get angry, like we do when we hit our foot against a door. And for you, Tom, it must be difficult to see Julie's anger at you, so I understand that you want to move away, or "duck behind a wall" as you put it."

\section{Evocative responding}

This involves the asking of open questions about tentative, unclear or emerging aspects of experience or responses, and helps partners expand and deepen their experience. The Latin word "evocare" means to call, and these questions call up client's primary emotions and their related habitual ways of signalling to and engaging with their spouse. The therapist 
asks when, what, where and how, focusing on specific elements of the client's experience. So the therapist asks Julie, "What happens to you as Tom turns away, like he did right now? You are trying to explain your feelings and he turns his head. What happened right here?" Julie replies, "I get angry but..." (She tears and shrugs). The therapist reflects this response and asks another evocative question. "That is when you get enraged - yes? But you also weep and shrug. What do the tears say?" Julie replies, "That it is hopeless. I can't get through to him. He just sees me as a nag. There is nothing I can do." The therapist reflects the despair and sadness implicit in this response and Julie begins to speak of her aloneness. This is a more primary response than her reactive anger.

\section{Heightening and interpreting}

The EFT therapist also heightens and interprets. Heightening involves repeating, re-enacting or using images and metaphors to enliven an experience. Interpretation is a conjecture that stays close to the client's experience but makes that experience more vivid, giving it color, shape or form and putting it in a particular meaning frame. The therapist might infer defensive strategies, core attachment feelings and longings and catastrophic fears. So the therapist says to Julie, "So behind the anger is all this hopelessness. The sense that you cannot connect - get through to Tom. That is, as you suggest, "So sad, so lonely". It is better to get angry than to stay in that sad, lonely place and give up on connecting with Tom, yes? (She nods). So you attack, raise your voice to be heard. Better to do that than to give up - lose your hope of being connected to Tom. You live with that all the time? (She nods). That is so hard. You are always afraid that he will not respond, so you put your armour on first?" (Julie laughs and agrees). The therapist then goes on to work with Tom concerning the emotions that cue his withdrawal and defensiveness in the relationship. She also links both partner's primary emotions, emotional signals sent to the spouse and the negative interactional cycle that results. This cycle is framed as having taken over the relationship and trapped both partners. So Julie begins to be able to talk about the panic and loneliness that happens just before her accusations and angry outbursts and how they push Tom away, and Tom is able to talk about his fear of criticism and how he then turns away and shuts her out, and so cues her panic.

\section{Tracking interactions}

The therapist tracks and reflects responses to the partner and interactional patterns and reflects them back to the couple. This allows them to see from a meta-perspective how their responses fit into a compelling feedback loop that creates an insecure bond for both of them. Particular interpretations or reframes are used to aid this process. The negative cycle between the couple is framed as their joint enemy that they have to be able to stop and move off to the side in their relationship. Primary emotions, such as Julie's fear of abandonment or Tom's fear of "being found wanting and deficient" are placed in the context of attachment theory. Tom's defensive turning away is framed as a response to his desperate fear of Julie's disapproval. This speaks to the fact that she is very important to him, rather than that he does not care about the relationship than her. Julie's anger is then framed as attachment protest and Tom's withdrawal as a defense against shame ("I can never make it with her - I am deficient") and helplessness ("I don't know how to please her so I just shut down and hope the fights will die down").

\section{Restructuring key interactions}

The final intervention used in EFT is the creation of enactments to restructure key interactions between partners. The therapist first attempts to heighten and distill a client's primary emotions and then structures the expression of these emotions to the other partner. The interaction that follows is then processed and integrated with each partner. Enactments can be used to heighten awareness of present positions, new emotions and responses. For example, Tom is gradually able to access his deep sense of failure and how this sense of "not knowing how to be a husband" cues his distancing from Julie. The therapist asks him to turn to his wife, look at her and share this with her. She then helps Julie respond, validating and softening any potentially negative reaction on Julie's part. Tom finds that he can share his self-doubts in a way that results in a sense of empowerment and more connection with his wife.

Enactments are especially powerful however as part of the choreography of the change events in EFT, withdrawer re-engagement (see the last chapter of Johnson, 2004 for an extended example of this event) and blamer softening. It is also clear from research how crucial a focus on emotions and evocative responding and heightening are in creating these events. So in a softening session, Julie is able to pull together the threads of her attachment fears and vulnerabilities, stay engaged with these emotions and clearly and congruently express to Tom that she is able to tell him, "I get so afraid that I do not really count with you - that you do not need me. That you will leave and I will be alone. I get so frantic that I just try to storm the wall between us. I need your reassurance so much. I feel so small and helpless when these feelings come. How can you really love me when I am so needy?" Here Julie discovers that Tom can stay and comfort her and in the process she begins to redefine her model of herself, her spouse and her relationship. The couple then begin to interact in a mutually accessible and responsive way, that is, they begin to build a more secure bond. 


\section{Final comments}

The EFT humanistic focus on process moments and patterns and on universal emotions allows this model to be applied to different kinds of people from different cultures and a variety of problems and impasses. The therapist respects and unfolds each person's idiosyncratic construction of reality and connectedness, while also using emotion and attachment needs and fears as the basis for empathic attunement. Problems that co-occur with relationship distress, such as depression, anxiety or traumatic stress are dealt with as they arise as an inherent part of unpacking and processing the present moment. A hopeless sense of despair, loss and unworthiness often accompanies withdrawal from an attachment figure, and fuels depression. Depression, in turn then heightens withdrawal and confirming negative feedback from the other partner.

Common impasses in couple therapy, such as blocks to the rebuilding of trust caused by key hurts, referred to as attachment injuries in EFT, can be effectively addressed in this model. A step by step process addressing the forgiveness of such injuries has been formulated (Makinen \& Johnson, in press) by studying case examples in a "bottom -up" fashion, observing the successful and unsuccessful completion of this forgiveness task and then testing the effectiveness of the model as created. Results suggest that EFT is very successful in helping distressed couples resolve such injuries. Furthermore, once these injuries are resolved, couples can complete the key change events in EFT and recover from relationship distress. These results also appear to remain stable over time.

The real strength of an experiential model such as EFT is that it is structured and scientific and yet flexible, responsive to each client and so created anew with each couple. The essence of science is observation and the finding of patterns in that observation. The 9 steps that make up EFT are: (1) assessment, (2) identifying the negative cycle, (3) accessing primary emotions in this cycle, (4) framing the cycle as the common enemy and creating conflict de-escalation, (5) deepening engagement with primary attachment emotions, (6) structuring the acceptance of these emotions by the other partner, (7) enacting these "new" emotions to create new positive trusting cycles, (8) consolidating changes into new stories and (9) attachment rituals and resolving pragmatic problems from the new secure base offered by the restructured relationship. These are based on the observation of the emotional responses and interactional moves of couples moving through the change process. It makes sense then that EFT fits very well with other observational findings such as those outlining marital distress and satisfaction by researchers such as John Gottman (1999), with research on the nature of emotion (Plutchik, 2000; Tomkins, 1991) and with the plethora of recent research on adult attachment (Cassidy \& Shaver, 1999). As well as being empirically tested, EFT interventions can be systematically taught (Johnson et al., 2005) and applied to varying populations of clients. Nevertheless, as a humanistic model, EFT couple therapy grounds every session in the safe haven of the relationship between therapist and client and in the shapes and colors of both partner's experiencing and moves in the interactional dance. For therapists and clients, each session is a time of genuine encounter and discovery. With this genuineness comes unpredictability, and in this is the art of therapy. The therapist takes what he is offered in the moment and makes it, with his clients, into something new. The therapist and the couple enter into what Rogers termed "the stream of becoming" (1961). Art and science comes together in the service of transformation.

\section{References}

Bowlby, J. (1969). Attachment and loss: Vol. 1. Attachment. New York: Basic Books.

Bradley, B., \& Furrow, J. (2004). Toward a mini-theory of the blamer softening event: Tracking the moment to moment process. Journal of Marital and Family Therapy, 30, 233-246.

Cassidy, J., \& Shaver, P. (1999). Handbook of attachment: Theory, research and clinical applications. New York: Guilford.

Clothier, P., Manion, I., Gordon Walker, J., \& Johnson, S. (2001). Emotionally focused interventions for couples with chronically ill children: A two year follow-up. Journal of Marital \& Family Therapy, 28, 391-399.

Damasio, A. R. (1994). Decartes error: Emotion, reason and the human brain. New York: Putnam

Gottman, J. M. (1999). The seven principles for making marriage work. New York: Crown Publishers.

Gross, J (2001). Emotional Regulation in Adulthood. Current Directions in Psychological Science, 10, 214-219.

Huston, T. L., Caughlin, J. P., Houts, R. M., Smith, S. E., \& George, L. J. (2001). The connubial crucible: Newlywed years as predictors of marital delight, distress, and divorce. Journal of Personality and Social Psychology, 80, 237-252.

Johnson, S. M. (2004). The practice of emotionally focused couple therapy: Creating connection (2nd Edn). New York: Brunner/Routledge.

Johnson, S. M. (2005a). Emotion and the repair of close relationships. In W. Pinsof \& J. Lebow (Eds.), Family psychology: The art of the science (pp. 91-113). New York: Oxford University Press.

Johnson, S. M. (2005b). Emotion and close relationships. In W. Pinsof \& J. L. Lebow (Eds.), Family psychology: The art of the science (pp. 91-113). New York: Oxford University Press.

Johnson, S. M. (2006). Integration in EFT: A reply to Simon. The Family Journal: Counseling and Therapy for Couples and Families, 14, $1-4$

Johnson, S. M. (2003). Attachment theory: A guide for couples therapy. In S. M. Johnson \& V. Whiffen (Eds.), Attachment processes in couple and family therapy (pp. 103-123). New York: Guilford Press.

Johnson, S. M., Bradley, B., Furrow, J., Lee, A., Palmer, G., Tilley, D., $\&$ Woolley, S. (2005). Becoming an emotionally focused couples therapist: The workbook. New York: Brunner/Routledge.

Johnson, S. M., \& Greenberg, L. S. (1985). The differential effects of experiential and problem solving interventions in resolving marital conflicts. Journal of Consulting and Clinical Psychology, $53,175-184$ 
Johnson, S. M., \& Greenberg, L. S. (1988). Relating process to outcome in marital therapy. Journal of Marital and Family Therapy, 14, $175-184$.

Johnson, S. M., Hunsley, J., Greenberg. L. S., \& Schindler, D. (1999). The effects of emotionally focused marital therapy: A metaanalysis. Journal of Clinical and Counselling Psychology, 6, 6779.

Johnson, S. M., \& Talitman, E. (1996). Predictors of success in emotionally focused marital therapy. Journal of Marital \& Family Therapy, 23, 135-152.

Makinen, J., \& Johnson, S. M. (in press). Resolving attachment injuries in couples using EFT: Steps toward forgiveness and reconciliation. Journal of Consulting and Clinical Psychology.
Plutchik, R. (2000). Emotions in the practice of psychotherapy. Washington, DC.: APA Press.

Rogers, C. (1951). Client-centered Therapy. Boston: HoughtonMifflin.

Rogers, C. (1961). On becoming a person. Boston: Houghton-Mifflin.

Stern, D. N. (2004). The present moment : In psychotherapy and everyday life. New York: W.W. Norton.

Tomkins, S. (1991). Affect, imagery and consciousness. New York: Springer.

Wiser, S., Golfried, M. R. (1998). Therapist interventions and client emotional experiencing in expert Psychodynamic-Interpersonal and Cognitive-Behavioral therapies. Journal of Consulting and Clinical Psychology, 166, 634-640 